\title{
LA PRUDENCIA O «EL ARTE DE BIEN VIVIR» (Y GOBERNAR) EN LA OBRA DEL JESUITA LUIS DE LA PUENTE
}

\author{
PRUDENCE OR «THE ART OF WELL-LIVING» \\ (AND GOVERNING) IN THE WORK OF THE JESUIT \\ LUIS DE LA PUENTE
}

\author{
DAVID MARTÍN LÓPEZ ${ }^{1}$ \\ Universidad de Castilla-La Mancha \\ http://orcid.org/0000-0002-3646-2499
}

RESUMEN: La obra impresa de Luis de la Puente se encuadra fundamentalmente en la teología ascética y moral. Sin embargo, dentro de su texto sobre los estados sociales y el camino de virtud que cada individuo podía recorrer, el jesuita reservó un espacio para reflexionar en torno al gobierno en general. Identificaba la política con la prudencia y, en sus páginas, el religioso presentaba cómo esta podía hacer del mundo un lugar mejor a través de la ética y la moral católicas.

Palabras clave: Luis de la Puente, prudencia, moral, política, gobierno

1. Este artículo se ha realizado en el seno del Proyecto de Investigación Nacional «La República política entre Clío y Caliope. Representaciones y prácticas políticas en la Monarquía Universal Hispánica en la Alta Edad Moderna» (referencia PGC2018-093833-B-I00) 
ABSTRACT: The works of Luis de la Puente are fundamentally framed in ascetic and moral theology. However, within his text about social status and the path of virtue that everyone can walk in their lives, the Jesuit set apart a space to meditate on the government in general. $\mathrm{He}$ identified politics with prudence and, in his pages, the religious presented how it could make the world a better place through Catholic ethics and morals.

Key words: Luis de la Puente, prudence, morals, politics, government

La prudencia es arte de vida, o por mejor decir, es arte de bien vivir, porque como la Medicina enseña a vivir con salud corporal y cura las enfermedades y preserva dellas, así ella enseña a vivir con salud espiritual, cura los vicios y preserva dellos. ${ }^{2}$

[...] la felicidad del Reino y la del Rey, que difícilmente se pueden distinguir y apartar, pues como dijo el Rey don Enrique Cuarto, La felicidad de un Rey es facer felices. ${ }^{3}$

\section{INTRODUCCIÓN}

El jesuita Luis de la Puente fue uno de los intelectuales más destacados de la Compañía de Jesús en el siglo XVII, lo cual habla mucho de sus capacidades y calidad de sus escritos, teniendo en cuenta la gran fama que tuvieron sus miembros en la época. Una notoriedad adquirida, no solo por la educación que aportaban a sus alumnos en los colegios que fundaron a lo largo y ancho del mundo, sino también por la formación que tenían sus miembros en las diferentes ramas del saber, como las lenguas clásicas (griego, hebreo y latín), matemáticas, astronomía, historia, derecho y, por supuesto, teología, entre otras. Fue en este último ámbito donde resaltó la pluma del jesuita vallisoletano, especialmente en sus vertientes moral y ascética. En sus obras se preocupó por presentar ejemplos virtuosos, como ocurre con las biografías edificantes del padre Baltasar Álvarez y Marina de Escobar, y en realizar textos que pudieran acercar el catolicismo tridentino a un mayor número de

2. LuIS DE LA PUENTE: Segundo tomo de la perfección del christiano en los estados y oficios de las tres repúblicas, seglar, eclesiástica y religiosa. Tratase más particularmente de la seglar: Valladolid, Francisco Fernández de Córdoba, 1613, pp. 599.

3. Juan Eusebio Nieremberg: Corona virtuosa y virtud coronada, Madrid: Francisco Maroto, a costa de Gabriel de León, mercader de libros, 1643, p. 115. 
fieles, como ocurrió con sus obras más importantes: Meditaciones de los misterios de nuestra santa fe (Valladolid, 1605; la Guía espiritual en que se trata de la oración, meditación y contemplación (Valladolid, 1609); y el póstumo Directorio espiritual. También escribiría un comentario sobre el Cantar de los Cantares y, por último, la obra sobre la que nos centraremos: De la perfección del christiano en todos sus estados (Valladolid, 1612-1614). ${ }^{4}$

La peculiaridad de nuestro análisis es que la teorización política no se encuentra en un tratado ad hoc, sino que es un texto de teología moral. El planteamiento de la obra de La Puente no tiene como dirección al rey, sino al conjunto de la población, clasificada por estados, de la misma manera que en el siglo XIV había hecho don Juan Manuel en su Libro de los estados. De esta forma, La Puente, como hicieron otros jesuitas en el tránsito del siglo XVI al XVII, dedicó sus cuatro volúmenes a las categorías sociales de religiosos, eclesiásticos y seglares. A este último caso destina el segundo volumen, publicado en 1613, donde trataría, entre otras cosas, de los estados del matrimonio, la viudez, la familia, la Corona... Así, podríamos entender que el ejercicio de la política no se circunscribía únicamente al gobierno de otros, sino que empezaría con el gobierno de uno mismo en todas sus actividades cotidianas.

La obra responde a la necesidad de establecer un modelo de comportamiento social basado en la virtud, que podría ser aceptado por todos los miembros del cuerpo de la Cristiandad, desde la cabeza a los pies, con independencia de su posición social, económica, política y nivel cultural. Siguiendo el clásico sistema organicista, sus enseñanzas cubrirían todos los ámbitos de la sociedad, desde el rey hasta el más modesto de los jornaleros, pasando por las diferentes realidades, tanto urbanas, como rurales. En todas y cada una de ellas, sus integrantes cumplirían un determinado papel para el bien y provecho del Estado, teniendo sus propios caminos de virtud que fueron presentados en esta obra lapontina, de la misma manera que se hizo en otras contemporáneas de Gaspar de Astete, Nicolás de Arnaya o Alonso Rodríguez, entre otros. ${ }^{5}$ Estas obras morales (con la de La Puente como ejemplo) fueron mecanismos de cohesión social y aportarían a los individuos elementos de identificación y pertenencia que los vinculasen al resto de la población desde un punto de vista religioso más que político. Como

4. Para conocer mejor la vida y obra de Luis de la Puente es ineludible la consulta de la amplia bibliografía escrita por Camilo Abad, especialmente El venerable P. Luis de la Puente de la Compañía de Jesús. Sus libros y su doctrina espiritual, Santander, 1954 y Vida y escritos del V. P. Luis de la Puente de la Compañía de Jesús (1554-1624), Santander, 1957. También pueden consultarse: Felipe Alegambe: Bibliotheca scriptorum Societatis Iesu, Antuerpiae, 1643, pp. 315-317; CArlos Sommervogel: Bibliothèque de la Compagnie de Jésus, Bruselas, París, tomo VI, pp. 1271-1295.

5. Un ejemplo de cómo estos «espejos de virtud» reflejaban los diferentes papeles que los individuos podían desarrollar en el mundo lo tenemos en la siguiente referencia, concretada en la vida familiar: DAVID MARTíN LóPEZ: «La virtud familiar en la tratadística moral jesuítica entre los siglos XVI y XVII», en MANUEL Rivero Rodríguez (coor.), Nobleza hispana, nobleza cristiana: la Orden de San Juan, Madrid, Polifemo, 2009, vol. 1, pp. 257-298. 
veremos en las próximas páginas, dentro del conflicto entre lo temporal y lo espiritual, esta obra abogaba por la preeminencia de lo segundo, que, por extensión, implica la superioridad del papa y la moral respecto al rey y la política. En este sentido, veremos cómo La Puente, sin escribir una obra política, al hablar de los diferentes niveles de gobierno tiene un trasfondo en el que de manera velada, participa de la crítica a la obra de Maquiavelo.

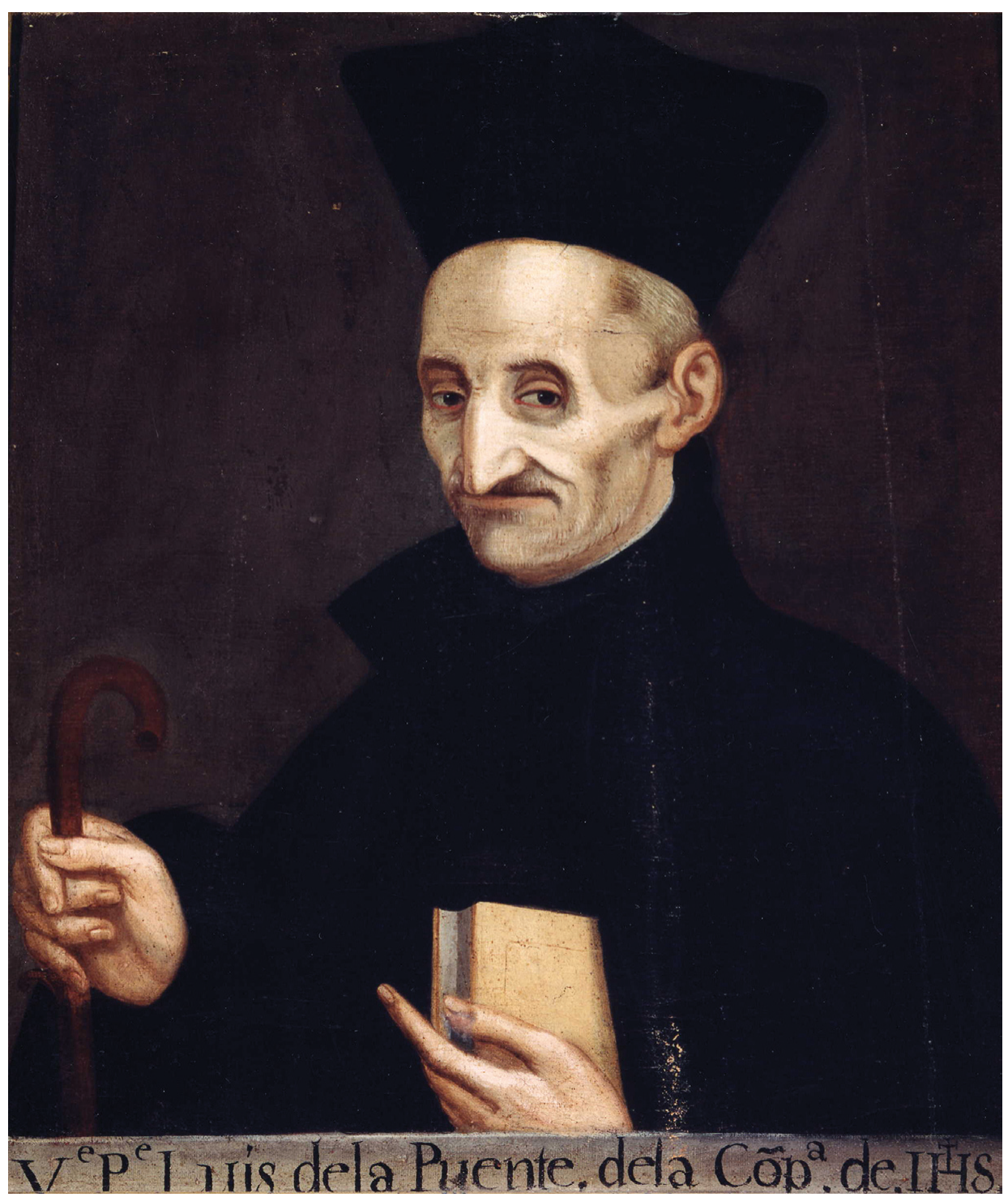

Fig. 1: Retrato del Venerable padre Luis de la Puente, de la Compañía de Jesús, Colegio de San Ambrosio, Valladolid 
El principal objetivo que pretendemos con este artículo no es solo poner de manifiesto el pensamiento del jesuita vallisoletano, sino también cómo la teología tenía su aplicación política en una sociedad confesional como la de la Edad Moderna. Pero también queremos establecer vínculos dentro de la producción moral y política jesuitas al observar relaciones entre las afirmaciones de La Puente con las de otros de sus hermanos de religión, también autores polifacéticos como Pedro de Ribadeneyra y Juan Eusebio Nieremberg. De esta manera, podremos observar cambios y continuidades a lo largo del medio siglo que dista entre el Príncipe Christiano del primero (1595) y la Corona virtuosa del segundo (1643).

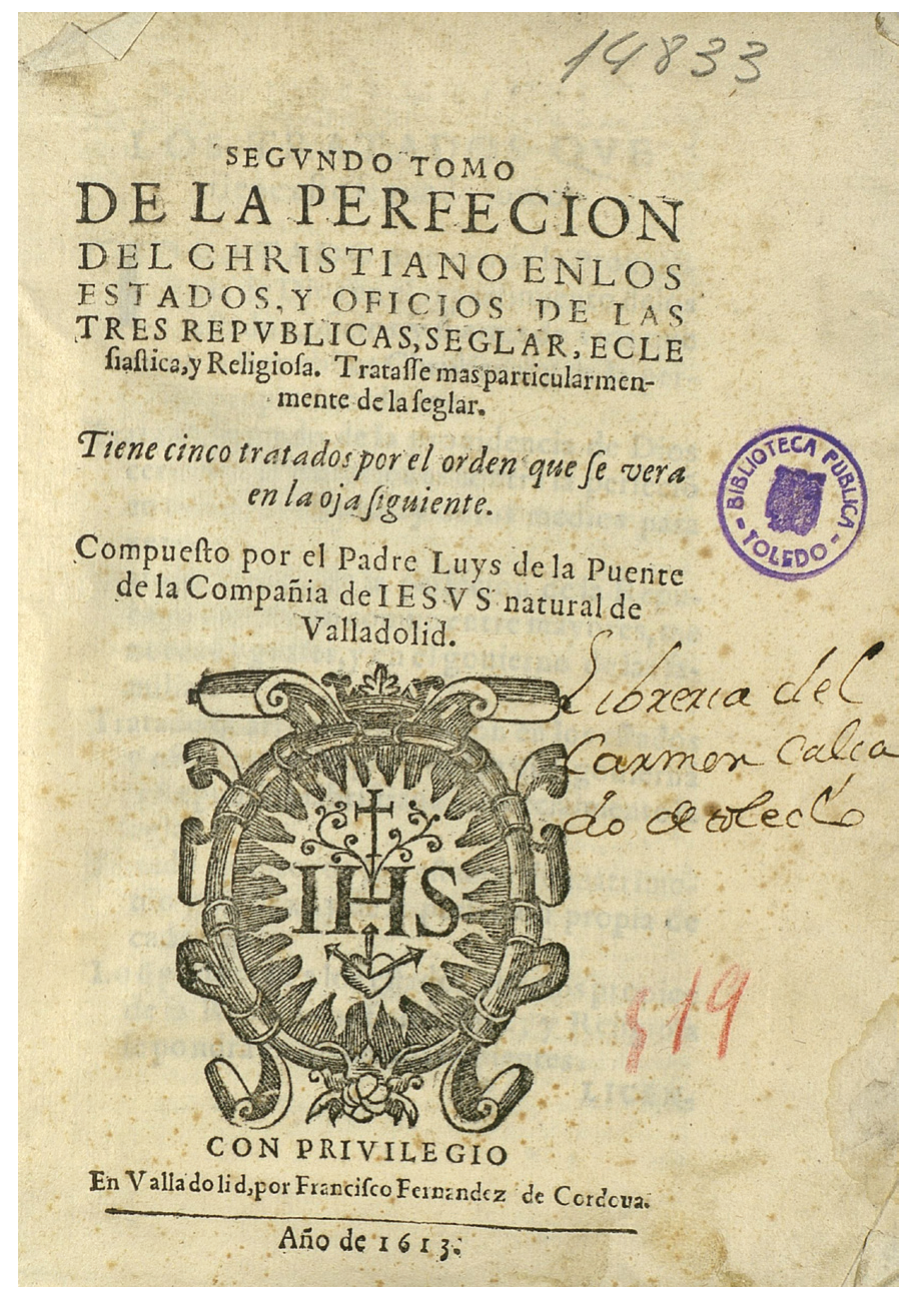

Fig. 2: Francisco Fernández de Córdoba, Portada del libro De la perfección del christiano en los estados y oficios de las tres repúblicas..., 1613, Valladolid. Biblioteca de Castilla-La Mancha, Toledo 


\section{LA PRUDENCIA COMO SINÓNIMO DE GOBIERNO}

Como la gran mayoría de autores políticos de la Edad Moderna, La Puente utilizó a Aristóteles y su diferenciación en tres tipos de regímenes políticos posibles, tanto en sus versiones positivas (monarquía, aristocracia y democracia), como en sus devenires corruptos (tiranía, oligarquía y oclocracia). Sin embargo, al hablar de cómo debía ser la política y en qué ámbitos y formas se desarrollaba, hace muy poco uso de ello. Atendió especialmente al caso del monarca, como veremos, por ser el nivel más alto y entender que era el mejor de esa tríada. No obstante, sus planteamientos y definiciones generales fueron muy amplias y, en cierta medida, al margen del paradigma aristotélico.

Para él, un Estado se correspondería con «una congregación de muchos hombres que se gobiernan por unas mismas leyes, tiene su perfección y felicidad fundada sobre dos insignes columnas, que podemos llamar verdad y virtud». ${ }^{6}$ La importancia de un régimen político no sería el número de personas que ostentaran el poder, sino el respeto a la justicia, una legislación acorde a las necesidades de los individuos y la búsqueda de la virtud por ellos. Así, podemos ver cómo en la misma definición del ámbito de acción del gobierno habría una crítica a las enseñanzas maquiavelianas, en el mismo momento en el que la ética y el cumplimiento de unas normas morales de comportamiento son uno de los pilares fundamentales.

Junto con el fundamento de esos dos pilares, La Puente establecía una serie de niveles de gobierno que partían de lo particular hacia lo general, pues «quien no tiene discreción para gobernar su casa, no la tendrá para gobernar la República».7 Además, situaba cinco niveles para el mundo civil, que tenían su reflejo también en el mundo religioso, aunque «de un modo más excelente»: monástico o singular, (o) económico, político, regnativo y militar, que se corresponden con el individuo, la familia, las ciudades, el rey y el ejército, respectivamente.

La prudencia se presentaba como la principal característica que debía tener un dirigente, hasta el punto de que a lo largo del texto se confunden e identifican los términos «gobierno» y «prudencia» para referirse a este elemento primordial, pues

[...] sin ella no se puede acertar en ningún género de gobierno, ni alcanzar las perfecciones que se han referido. La prudencia enseña a juntar humildad con magnanimidad, magnificencia con templanza, celo de justicia con clemencia y pone freno a los fervores del celo [...] es guía de las obras, moderadora de

6. Luis de la Puente: Segundo tomo de la perfección..., p. 366.

7. Ibidem, p. 601. 
los afectos y maestra de las costumbres. Quitada la prudencia, la virtud se convierte en vicio, el afecto natural en turbación y destrucción de la misma naturaleza. ${ }^{8}$

La prudencia inundaba todo lo político hasta tal punto que la teoría política lapontina se explicaría a través de saber qué es la prudencia, en qué consiste, cómo se debe hacer uso de ella en los diferentes ámbitos de la vida y de qué manera la puede aprender y perfeccionar el gobernante en cualquiera de sus niveles. Al margen de esta cuestión, el concepto de prudencia que exponía el jesuita se correspondía con lo común en la tratadística política de la época. Basándose en el ejercicio del consejo, el juicio y el imperio, ${ }^{9}$ debía conocer los hechos antes de actuar, pensar cuáles eran los medios más oportunos, resolver lo más conveniente y, finalmente, ejecutar lo dispuesto de manera inmediata para evitar distracciones y obstáculos. ${ }^{10}$ Los elementos que debía conocer el dirigente para llevar a buen puerto ese gobierno prudente inciden en los lugares comunes transmitidos por escrito, e incluso de manera iconográfica, como es el caso de la «Alegoría de la prudencia» de Tiziano (1565-1570). ${ }^{11}$ El dominio del espacio y del tiempo era la primera característica que señalaba La Puente como fundamental para un gobierno prudente. La necesaria comprensión de los distintos humores existentes en los territorios y las personas a su cargo afirmarían la diversidad de identidades, afectos y comportamientos existentes por aquel entonces en la Monarquía Hispánica (o Católica), donde el monarca español tendría posesiones en Europa, Asia, África y América en el momento de publicación del tratado lapontino (1613). Respecto al control del tiempo, no se refiere tanto a la actuación más o menos decidida y rápida en la ejecución de las decisiones, sino en cómo el conocimiento del pasado debía servir para el gobierno presente y futuro. En este sentido, como haremos hincapié en el siguiente apartado cuando hablemos del caso de los reyes, ese saber estaría basado en la Historia a través de los ejemplos edificantes de otros gobernantes anteriores, ${ }^{12}$ pero

8. Ibidem, pp. 598-599.

9. Así también se expresaba el padre Nieremberg unos años después. JuAN Eusebio NieremberG: Obras y dias. Manual de señores y príncipes en que se propone con su pureza y rigor la especulación y ejecución política, económica y particular de todas las virtudes, Madrid, 1629, fol. 241r.

10. María Montesinos Castañeda: «Prudente gobierno: la prudencia en el gobernante», en Potestas. Estudios del Mundo Clásico e Historia del Arte, 14, 2019, pp. 61-83.

11. Puede consultarse un completo análisis de esta obra y las fuentes que pudieron motivar su conceptualización en RAFAel ZAFrA: «El prudente Tiziano y su emblema de la prudencia», en Potestas. Estudios del Mundo Clásico e Historia del Arte, 3, 2010, pp. 123-146.

12. La literatura edificante fue un género ampliamente desarrollado durante el Siglo de Oro español y el uso de ejemplos en pleno texto era muy usual para apoyar lo que se decía, sobre todo en la literatura política. Un caso perfecto para comprender el uso de estas obras es la Corona virtuosa de Nieremberg. Dedicada al príncipe Baltasar Carlos, reserva casi 200 páginas (de 359 totales) a mostrar ejemplos concretos de monarcas castellanos y de la Casa de Austria. JuAn Eusebio Nieremberg: Corona virtuosa y virtud coronada. En que se proponen los frutos de la virtud de un Príncipe, juntamente con los heroicos exemplos de virtudes de 
también en el conocimiento de primera mano de aquellos consejeros sabios y ancianos de los que se rodearía. Así, junto con la práctica, se conseguiría la experiencia necesaria para gobernar bien y que solo se podría conseguir con el transcurso «de varias vidas». ${ }^{13}$ Ello, «para escoger el bien de donde se ha de seguir [...] para mayor provecho», pudiéndose anticipar a lo que pasará y actuar «antes que crezcan y causen mayor daño». ${ }^{14}$

Pero no solo era importante saber qué había ocurrido antes y la forma en la que otros habían podido solucionar problemas similares a los que el gobernante se pudiera enfrentar. Debían mirar al pasado, pero sin perder de vista el presente. Por ello, La Puente concedía también mucha importancia al conocimiento de los recursos de los que disponía, como «las provisiones de importancia que están a su cargo y de las personas más calificadas que le ayudan o pueden ayudar en su gobierno, de los servicios que le han hecho y hacen para premiarlos, o de los delitos para castigarlos». ${ }^{15}$ Para tener todo esto en cuenta, era necesario que tomara nota de ello en una serie de libros que pudiera consultar cuando el momento lo precisara.

Aparte de eso, La Puente distinguiría entre el buen gobierno y el buen gobernante, con una evidente contradicción: el primero, lo sería en función de los resultados obtenidos, teniendo en cuenta la obediencia de sus subordinados como un elemento clave en el análisis; el segundo, lo sería en función de sus características y virtudes intrínsecas, sin tener en cuenta los resultados que obtuviera, puesto que dependían de aspectos ajenos a su persona. Ahí radica la contradicción que observamos, ya que si el dirigente era virtuoso y bien formado en el arte de la prudencia, haciendo uso de aquellos instrumentos a los que haremos mención más adelante, los resultados debían de ser positivos y de provecho. Si la afirmación quedara ahí y el religioso no hiciera hincapié en la virtud y la moral como ejes del gobierno en el resto de su obra, podríamos incluso pensar en un posible síntoma de tacitismo, ese maquiavelismo encubierto que tan bien estudió José Antonio Maravall. ${ }^{16}$

los emperadores de la casa de Austria y Reyes de España, Madrid, 1643, pp. 116-312; Antonio AlvAREZOssorio Alvariño: «Virtud coronada: Carlos II y la piedad de la Casa de Austria», en P. Fernandez ALbaladejo, V. Pinto Crespo y J. Martínez Millán (coords.), Política, religión e inquisición en la España Moderna, Madrid, 1996, pp. 29-57.

13. Luis de la Puente: Segundo tomo de la perfección..., p. 610; Pedro de Ribadeneyra: Tratado de la religión y virtudes que deve tener el Príncipe Christiano para gobernar y conservar sus Estados, Madrid: imprenta de P. Madrigal, 1595, pp. 407, 410.

14. LuIS de LA PUENTE: Segundo tomo de la perfección..., p. 612

15. Ibidem, p. 609.

16. José Antonio Maravall: «La corriente doctrinal del tacitismo político en España», en Estudios de Historia del Pensamiento Español, Madrid, CEPC, 1999, vol. 3, pp. 75-98. 


\section{LA PRUDENCIA Y EL MONARCA}

Aunque el conjunto de la obra que estamos comentando no entraría exactamente dentro de la literatura especular que tanta profusión tuvo dentro de la tratadística política desde la Baja Edad Media, el jesuita vallisoletano reservó el cuarto apartado del segundo volumen a «los estados y oficios más insignes de los que gobiernan la República Christiana, especialmente la seglar». ${ }^{17}$ En ese cuarto tratado reserva un espacio a la figura del monarca, a pesar de que, como hemos comentado anteriormente, no tuviera un papel predominante en la definición que daría el jesuita sobre lo que serían la República y el Estado.

Este apartado sobre el gobierno seglar trataría unas temáticas y tendría unas intenciones muy similares a las de otros tratados políticos que surgirían de las plumas de sus hermanos de religión antes y después de la obra de La Puente. ${ }^{18}$ La idea principal sería mostrar a Felipe III, al que se dedica la obra completa en el primer volumen, cuáles deberían ser las características del monarca, su instrucción, la forma de ejecutar el gobierno y los instrumentos de los que debía hacer uso para el buen desempeño de sus obligaciones. El predominio de lo religioso sobre lo temporal que sobrevuela en el texto lapontino tendría su explicación en el contexto en el que se produjo, tanto dentro de la propia Orden ignaciana, como, sobre todo, si ampliamos las miras al conjunto de la Monarquía Hispánica. Hay que tener en cuenta el proceso de acercamiento que se produjo entre Madrid y Roma desde finales del siglo XVI y, sobre todo, en las primeras décadas del XVII, que tuvo como consecuencia lo que Martínez Millán ha definido como un cambio de paradigma dentro de la monarquía peninsular: el paso de la Monarquía Hispánica a la Monarquía Católica, ${ }^{19}$ que no es otra cosa que el cambio en las relaciones entre la Corona y el Papado con un creciente influjo de este

17. En la edición del primer volumen de la obra, publicado en 1612, se presentaba una tabla general de los tres tomos que fueron publicándose en los años siguientes. En ese caso, el tratado dedicado al gobierno de la república seglar ocuparía el tercer lugar. En la edición de 1613, que es la que nosotros seguimos, este tratado permutaría su lugar con el dedicado al gobierno familiar, que era antecedido por una serie de reflexiones sobre «el trato común entre mayores, menores e iguales». En este caso, al igual que observamos una continuidad lapontina en la obra política de Nieremberg, se puede ver una permanencia de conceptos y expresiones con el Príncipe Christiano de Ribadeneyra, que también dividía el gobierno en la sociedad entre «mayores» $\mathrm{y}$ «menores» $\mathrm{o}$ «superiores» $\mathrm{e}$ «inferiores».

18. Durante el reinado de Felipe II, con el fin de aportar a la formación del príncipe, aparecieron el Príncipe Christiano de Ribadeneyra (1595), la Philosophia moral de Príncipes de Juan de Torres (1596) y el De Re et Regis institutione de Juan de Mariana (1599). Después, ya durante el reinado de Felipe IV, se escribieron las Obras y días (1629) y la Corona virtuosa (1643) de Nieremberg, entre otras. Para más información sobre la impresión de estos tratados: DAvid MARTín López: «La conceptualización del Príncipe Christiano en la tratadística jesuítica entre los siglos XVI y XVII», en ANTONIO JimÉnEZ EsTRELla y Julián José LozANO Navarro (eds.), Actas de la XI Reunión Científica de la Fundación Española de Historia Moderna, Granada, FEHM, 2012, vol. 1, pp. 113-123.

19. J. Martínez Millán y M. A. Visceglia (coords.): La monarquía de Felipe III, Madrid, Mapfre, vol. 1, 2007 
sobre aquella. Por resumir brevemente, en ese proceso fueron importantes: la influencia religiosa del entorno familiar del por entonces príncipe Felipe, que tuvo su continuación y crecimiento durante su reinado; también tuvo su papel dentro del proceso vivido en esas primeras décadas del siglo XVII el apoyo que recibió la espiritualidad descalza o recoleta, ${ }^{20}$ de corte radical y riguroso; de la misma manera, la «deshispanización» de la Compañía de Jesús, que a lo largo de aproximadamente un siglo no tendría un general de origen español para evitar injerencias del monarca hispano sobre estos religiosos. Este viraje en la concepción de la monarquía que se viene analizando en los últimos años estaría apoyado por la cantidad de obras que imprimió la Iglesia en esas décadas, cuyos contenidos irían en la misma línea de lo que veremos a continuación que escribió el jesuita.

Volviendo al texto, a pesar de tratar temáticas similares a las de los tratados que son específicamente políticos, la peculiaridad de la obra lapontina sería la puesta común y la relación de factores entre los diferentes niveles de gobierno a los que ya hemos hecho mención anteriormente. En este segundo volumen, junto al gobierno seglar, que se reconocería con el monarca, fundamentalmente, también se hace mención al gobierno oeconómico de la familia y las formas que tendría el individuo de regirse dentro del matrimonio y la viudez, tanto a nivel masculino, como femenino.

La Puente guarda este espacio al monarca porque, al igual que reflejaban el resto de los moralistas que escribieron lo que podríamos denominar como «caminos/espejos de virtud social», cuánto más arriba se estuviera en la escala social, más posibilidades habría de pecar, «como si la grandeza del estado abonase el ejercicio vicioso, y ocasionado a pecados, y no le hiciese digno de mayor castigo por el mayor daño del escándalo». ${ }^{21}$

La Puente organizaría su discurso en torno al rey en cuatro apartados: su situación en la sociedad y la relación con sus súbditos; el origen de su poder; los aspectos que debían conformar su persona; y el modo en que llevar a cabo el gobierno, que iría ligado al último apartado de nuestro texto. Para el primero de ellos, emplearía la clásica concepción organicista de la sociedad, en la que a cada individuo le correspondía un oficio y una posición en el cuerpo del Estado. Como es lógico, al rey se le asignaría la cabeza, por ser lo más visible del cuerpo, pero también por ser el órgano director, desde el que se envían las instrucciones al resto. También emplea La Puente la icónica

20. José García Oro: «Observantes, recoletos, descalzos. La Monarquía católica y el reformismo religioso del siglo XVI», en Teófanes EgIDo López (coor.): Actas del Congreso Internacional Sanjuanista. Ávila, 1991, vol. II, 53-97; José García Oro y Ma José Portela Silva: «Los frailes descalzos. La nueva reforma del Barroco», en Archivo Ibero-Americano, 60, 2000, pp. 511-586.

21. Luis de la Puente: Segundo tomo de la perfección..., pp. 558-559. 
imagen del rey como piloto de una nave, que tiene como principal objetivo llevar a buen puerto a su tripulación sin que naufrague. ${ }^{22}$

A partir de ese planteamiento organicista y asignando al monarca un puesto fundamental para el devenir del cuerpo del Estado, La Puente desarrolla una teoría providencialista del gobierno. ${ }^{23}$ En ella, señala que los bienes y males de un reino serían recompensas y castigos divinos en función del comportamiento virtuoso o pecador de su monarca. Los aciertos y torpezas de la vida del rey tendrían su influjo en sus súbditos. ${ }^{24}$

El origen del poder monárquico fue también un tema recurrente en la tratadística política de la época, con diversidad de opiniones entre los propios escritores jesuitas. ${ }^{25}$ En la línea de lo que venimos comentando, La Puente señalaría que el poder del rey sería teocrático y que no solamente procedería directamente de Dios, sino que también estaría subordinado a la jerarquía de la Iglesia, que siempre se encontraría por encima del monarca:

El rey y gobernadores deben guiarse por los preceptos de la religión cristiana, para lo cual deben seguir los consejos de los eclesiásticos porque en las cosas que pertenecen a la Ley y Religión Christiana, los sacerdotes son superiores a los reyes, y el sumo sacerdote de la Iglesia, que es el Papa, es maestro y guía de todos [...] Los sacerdotes son más excelentes en la dignidad que los demás hombres, aunque sean Reyes [...] Para que entiendan los Príncipes de la tierra como se han de conservar en humildad, procurando no se levantar con soberbia sobre sus hermanos y mucho menos sobre los sacerdotes, sino contentarse con su Principado, sin usurpar una partecica del Eclesiástico, sopena de que les quitará Dios uno y otro y perderán mucho de lo propio, por haberse entremetido en lo ajeno [...] porque no consentirá Dios esta junta en su Iglesia, cuya dignidad sacerdotal ha de llevar tras sí a la Real y no la Real a la Sacerdotal. ${ }^{26}$

22. Ibidem, pp. 518-519; Pedro de Ribadeneyra: Tratado de la religión..., pp. 174-176; JuAn Eusebio Nieremberg: Corona virtuosa..., pp. 31-32.

23. Para más información sobre los escritos providencialistas del Siglo de Oro hispano: SANDRA CHAPARro: Providentia. El discurso político providencialista español de los siglos XVI y XVII, Madrid, Comillas, 2012, especialmente las páginas 174-178 y 183-188, en las que se centra en Ribadeneyra y Nieremberg, respectivamente.

24. Este fue el leitmotiv del Tratado de la Tribulación de Ribadeneyra (1589), en el que haría directamente responsable del desastre de «la Invencible» a Felipe II por los conatos de regalismo que significaron los recursos de fuerza ante los tribunales eclesiásticos y la organización de una visita a las provincias españolas de la Compañía de Jesús por un religioso ajeno a la Orden.

25. Ribadeneyra y Nieremberg, al igual que La Puente, afirmarían que el poder del rey procede directamente de Dios. Sin embargo, otros como Juan de Mariana y Francisco Suárez se decantaron por un camino en el que Dios concedía el poder a la comunidad, que era la que lo otorgaba al gobernante, pudiendo quitárselo en el caso de que este deviniera en tiranía e injusticia. JAVIER BurRIEZa SánCHEZ: «Los jesuitas como fuerza intelectual política», en Francisco José Aranda Pérez y José DAmião Rodrigues (eds.): De Re Publica Hispaniae. Una vindicación de la cultura política en los reinos ibéricos en la primera modernidad, Madrid, Sílex, pp. 244, 255-258.

26. Luis de la Puente: Segundo tomo de la perfección..., pp. 565-566, 538. 
Como no podía ser de otra manera y ya hemos apuntado más arriba, el buen y recto comportamiento del rey se correspondería con los valores de la ética cristiana y la moralización del ejercicio del gobierno, «despolitizando» la política y alejándose de lo presentado por Maquiavelo casi un siglo antes, como hicieron en bloque buena parte de los escritores religiosos hispanos. ${ }^{27}$ Las virtudes de raíz cristiana estarían por encima de cualquier capacidad y conocimiento en la instrucción y desempeño de todo monarca. La primera de todas ellas sería la magnanimidad, fundada en cinco actitudes o formas de hacer frente al mundo: pretender cosas «de grande honra» por la virtud que encierran en sí mismas y no tanto por el interés que pudiera haber en ellas, que es donde se encontraría la segunda, basada en su desprecio; emplear la grandeza y el poder en hacer bien a otros y lograr que crezcan y mejoren sus condiciones de vida; no hacer cosa indigna, injusta ni caer en el menosprecio de los subordinados; finalmente, afrontar con buen ánimo el devenir de los acontecimientos, tanto si fueran positivos, como negativos. ${ }^{28}$ En conclusión, el concepto de magnanimidad de La Puente consistiría en una forma de vida basada en la resiliencia, la justicia, la caridad y la falta de ambición y codicia. Como vemos, todo visto desde el prisma de la ética católica.

Junto a esta característica, se situaban la misericordia y la clemencia como dos elementos que debían resaltar en la forma de ser de todo monarca al tratar con sus súbditos. Respecto a la primera, debía cuidarse del dominio de las pasiones por los diferentes inconvenientes que podrían provocar, tanto físicos (pérdida de la «sustancia, fortaleza y vigor de cuerpo y alma»), ${ }^{29}$ como materiales, por los grandes gastos que ello podría ocasionar. Respecto a esto último, resulta llamativo que La Puente haga referencia al consumo de recursos procedentes del «gusto por las mujeres deshonestas», señalando solo el perjuicio material del mismo, sin entrar en disquisiciones morales acerca de la prostitución y el adulterio. Siguiendo con la gestión de esos recursos, el rey debía organizar su tiempo de manera equilibrada, permitiendo un tiempo para el ocio, pero sin llegar al exceso, pues podía alejarle «de las cosas de Dios y las ocupaciones del gobierno»..$^{30}$

En cuanto a la segunda, debía ejercer la clemencia con orden y control, tratando de evitar tanto el perdón excesivo, que le restaría autoridad, como la rigurosidad y celo en el cumplimiento de las leyes, que provocaría el alejamiento, el temor y, en consecuencia, el enfrentamiento y las revueltas. En este sentido, La Puente hizo menos hincapié en este detalle que Juan de

27. José María IÑurritegui Rodríguez: «Filósofos y santos: la Philosophia moral de Juan Torres y la definición de la cultura política católica», en Antonio Mestre Sanchís, Pablo Fernández Albaladejo y EnRiQue Giménez López (coords.), Monarquía, Imperio y pueblos en la España Moderna. Universidad de Alicante, Asociación Española de Historia Moderna, 1997, vol. 1, p. 654.

28. Luis de la Puente: Segundo tomo de la perfección..., pp. 536-538.

29. Ibidem, p. 553.

30. Ibidem, pp. 558-559. 
Mariana en su De Rege y que le valieron multitud de críticas y censuras por lo que se entendió como una defensa y justificación del tiranicidio. ${ }^{31}$ Quizás por el revuelo que el talaverano había provocado en la década anterior, o por las directrices que se habían enviado desde Roma para que los jesuitas se distanciaran de ese tipo de temáticas hasta llegar a su prohibición, La Puente lo deja únicamente como un aviso, sin entrar demasiado en los medios por los cuales la comunidad podría actuar legítimamente para destronar a un tirano. A través de Séneca y su De clementia y las palabras del profeta Isaías, la clemencia y la misericordia irían de la mano de la precaución antes que del ejercicio de la justicia, pues esta segunda se podría evitar a través de la primera:

[...] que los Reyes y Gobernadores se precien de ser muy clementes y misericordiosos y muestren su poder no tanto en matar delincuentes, cuanto en atajar y remediar los delitos. Y si bastan amenazas, no procedan castigos. $^{32}$

\section{LOS INSTRUMENTOS DE LA PRUDENCIA Y EL GOBIERNO DEL REY: CONSEJO, JUSTICIA Y EJÉRCITO}

Aunque el monarca fuera la pieza clave de ese cuerpo del Estado y el ejercicio de la prudencia se basara en la moral y virtudes católicas a las que hemos hecho referencia anteriormente, el rey necesitaba hacer uso de una serie de componentes que facilitasen su labor. En este sentido, la religión no sería uno de ellos, ni el rey la manejaría a su capricho y en función de las circunstancias, como había expresado Maquiavelo. Como estamos viendo, la moral católica sería la que rigiera todas las decisiones de gobierno y estaría detrás de todos aquellos elementos que le ayudaran en el ejercicio de la prudencia. Entre ellos, destacamos la importancia que dio al consejo, la justicia y al ámbito militar.

Respecto al primero de ellos, La Puente teoriza y reflexiona en torno a cómo el rey debía hacer uso del consejo, si es que debía hacerlo, cuántos

31. En esencia, las intenciones de La Puente y de Mariana serían las mismas al avisar al rey de que el exceso de rigor en el gobierno podía desencadenar en quejas y rebeliones y que, por ello, debía moderar su ejercicio y ser justo en sus decisiones. Sin embargo, la obra del talaverano levantó muchas suspicacias por las relaciones que algunos quisieron ver entre el contenido de sus páginas y los asesinatos en Francia de Enrique III y Enrique IV. Pero la relación entre la publicación del De Rege y ambos magnicidios, que tanto pábulo tuvo en la época, es algo que hoy en día se pone en entredicho. A. MERLE: «El De Rege de Juan de Mariana (1599) y la cuestión del tiranicidio: ¿un discurso de ruptura?», Criticón, 120-121, 2014, pp. 89102; Fernando Centenera Sánchez-Seco: El tiranicidio en los escritos de Juan de Mariana, Madrid, Dykinson, 2009.

32. Luis de la Puente: Segundo tomo de la perfección..., pp. 594-595; JuAN Eusebio NieremberG: Corona virtuosa y virtud coronada..., p. 88. 
consejeros debía tener y cuáles eran las materias sobre las que debía ocuparse. En todo caso, siempre se refiere a las personas que el rey debía tener a su alrededor, pero nunca a la institución del Consejo, un órgano de gobierno ampliamente desarrollado en la Monarquía Hispánica en la que vivió La Puente. Lógicamente, entendemos que los miembros de los consejos (Estado, Guerra, Hacienda, Indias, etcétera) tenían como principal función proponer, sugerir, plantear ideas al rey en función de las competencias que tuviera cada consejo, pero el religioso en ningún momento habla de instituciones, sino de individuos que tratan los temas personalmente.

Ante todo, considera algo esencial que el rey no ejerza de manera absoluta, sin que haya nadie a su alrededor que ponga objeciones a sus mandatos, por ser muestra de vanidad y soberbia, aparte de porque así el gobierno fácilmente devendría en tiranía. En el momento de tomar una decisión, La Puente defiende la existencia de diversas opiniones, caminos y planteamientos, puesto que ver la realidad desde un prisma poliédrico le ayudaría a comprender mejor lo que ocurría y, en consecuencia, entender mejor cuáles debían ser los actos que podía acometer. La consulta con más personas y la revisión de diferentes horizontes de actuación le concederían legitimidad a sus decisiones.

Lo concibe como algo tan necesario, que incluso en el caso de que se diera la situación de un monarca con grandes y acertados saberes, también se debía rodear de ministros con los que debatir, pues, como afirma, «ven más cuatro que dos»y «el sabio, oyendo se hace más sabio». ${ }^{33}$ Para el jesuita, el conocimiento es infinito y siempre hay que tratar de trabajar por saber algo más, pues ello redundará en la virtud del propio individuo y en la de los que le rodean. Si los aportes se hacían con sentido y conveniencia, serían beneficiosos tanto para el que los escucha, como para el que los da.

El número de consejeros que debía tener el monarca es una materia sobre la que incide el religioso e incluso da un número exacto de cuál sería la cantidad ideal entre muchos y pocos. Antes, descarta las otras opciones, empezando por que el rey consulte a muchos, puesto que, si no se ponen de acuerdo, al ser muchos puede emborronarse el asunto y no llegar a una solución. De la misma forma, rechaza que sean uno o dos porque ello conllevaría un gobierno basado en solo dos planteamientos, que no tenían por qué ser los idóneos. Aquí podemos encontrar una crítica a la situación en la que se encontraba Felipe III y el predominio de los intereses del duque de Lerma en la toma de decisiones. Los argumentos son continuos en contra de la existencia de un solo consejero y el mantenimiento en su puesto por parte del rey a pesar de la corrupción o intereses que podían mostrar sus movimientos y propuestas. Frente a esto, La Puente, a diferencia del resto de

33. Luis de la Puente: Segundo tomo de la perfección..., p. 614. 
tratadistas políticos consultados, propone que el término medio de consejeros se encuentra en el siete, un número recurrente dentro de la religión católica por ser esa cantidad los sacramentos, las virtudes cardinales, los dones del Espíritu Santo y los pecados capitales. Para dar tal cantidad, La Puente se apoya en el Apocalipsis:

[...] hay siete espíritus que asisten dentro del trono de Dios y le ayudan al gobierno de los hombres, no porque tenga necesidad de consejeros, sino para significar lo que han de hacer los Reyes y Gobernadores, que tienen necesidad dellos. ${ }^{34}$

Expuesta su cantidad, el jesuita continuaba señalando al rey cómo debía elegirlos, en qué aspectos se tenía que fijar y cuáles serían sus características para que ejercieran su función de la manera más eficaz posible. Era fundamental seguir la tríada basada en la experiencia, la religión y la sabiduría, que debían ir acompañadas de virtudes como moderación, caridad, piedad y fortaleza. ${ }^{35}$ Así, La Puente acude una vez más a un lugar común dentro de la tratadística política, señalando a un anciano como ejemplo de buen consejero, que con el paso de los años habría adquirido experiencia y, con ella, conocimientos suficientes para aportar buenas ideas. Además, el rey debía rodearse de personas expertas en diferentes materias para tener esa visión poliédrica que mencionábamos anteriormente $\mathrm{y}$, ante todo $\mathrm{y}$ siempre que se pudiera, que los consejeros fueran religiosos. Como estamos comentando a lo largo de estas páginas, La Puente situaba nuevamente a la religión en un peldaño por encima del resto del mundo. En el caso que estamos viendo del consejo, tampoco debe resultar llamativo ni sorprendente si tenemos en cuenta la labor confesional y de dirección de conciencias que llevaron los jesuitas en los diferentes ámbitos de la sociedad. ${ }^{36} \mathrm{Al}$ margen de esa preferencia religiosa, resulta interesante cómo La Puente amplía a todo el espectro social la posibilidad de acceder al cargo de consejero, con independencia de su pertenencia a un determinado estrato social. No le importaba que la persona fuera rica o pobre, noble, agricultor o mercader, pues lo importante sería su calidad espiritual. En todo caso, se pone del lado de los trabajadores manuales y no de los ricos y poderosos:

Cuando las ciudades están en semejantes aprietos, y no pueden librarlas dellos, ni las riquezas de los ricos, ni las armas de los fuertes, ni los mandatos de los

34. Ibidem, p. 617.

35. Ibidem, pp. 618, 621-626.

36. Javier Burrieza SÁNChez: «La Antigua Compañía de Jesús (siglos XVI-XVIII)», en TeÓFAnes Egido (coor.): Los jesuitas en España y en el mundo hispánico, Madrid, Marcial Pons, 2004, p. 120; JuliáN José Lozano Navarro: La Compañía de Jesús y el Poder en la España de los Austrias, Madrid, Cátedra, 2005, p. 53. 
poderosos, y hállase entre ellos un varón pobre y sabio [...] el cual, con su oración y con su mucha prudencia y discreción da traza como librarles del peligro y sacarles del aprieto, en el cual perecieran sino fuera por su buen consejo. Porque para tales casos más vale la sabiduría que la fortaleza y más hace la prudencia que los muchos instrumentos de guerra. Pero pasado el aprieto, todos se olvidan del pobre, porque los mundanos no precian sino a los ricos y poderosos, y a los grandes y solamente hacen caso de los pobres sabios cuando tienen necesidad dellos. ${ }^{37}$

Junto a los aspectos positivos en los que debía fijarse el rey en la búsqueda y localización de aquellos que pudieran aconsejarle mejor, La Puente también señala cuáles debían ser las cuestiones de las que se debía alejar, puesto que el rey sería el principal culpable de un mal consejero por haber puesto a esa persona en su cargo. El gobierno perdía legitimidad si era aconsejado por torpes e interesados. Sería imposible que cumpliera con las cualidades inherentes a su cargo si el individuo era vicioso, murmurador, con «mala voluntad y el gusto estragado» y asesoraba en función de los beneficios que podía extraer de ellos. ${ }^{38}$ Con este último detalle es inevitable volver a pensar en la figura de don Francisco Gómez de Sandoval y Rojas.

Una vez elegidos, no bastaba con que el rey hubiera acertado en la selección, sino que también tenía que hacer buen uso, consultándoles sobre las temáticas que mejor conociera cada uno de ellos y en el momento adecuado. Ese oportunismo no solo era cuestión del monarca, sino que el consejero también debía analizar bien las circunstancias y, en función de sus conocimientos, tener el dominio suficiente para saber llevarlos a la práctica y que estos fueran útiles y no mera especulación. ${ }^{39}$ Otro aspecto importante que debía caracterizar el ejercicio práctico del asesoramiento es que se hiciera en situación de libertad. Aunque el rey no estuviera de acuerdo con las propuestas que le hicieran los consejeros, estos debían opinar sin pensar en los posibles inconvenientes y castigos que podrían sucederles. De lo contrario, se convertirían en lisonjeros y aduladores, que más que el bien de la república, pensarían en cuidarse a sí mismos. ${ }^{40}$

El segundo instrumento de gobierno para La Puente sería el ejercicio de la justicia, identificando al monarca con su recto desempeño y aplicación

37. Luis de la Puente: Segundo tomo de la perfección..., pp. 618-619. Esta preferencia está en la misma línea que mostraron otros jesuitas como Francisco Escrivá y Pedro de Guzmán que elogiaron en sus obras el trabajo manual como respuesta al pecado de la ociosidad. Francisco Escrivá: Discursos de los estados de las obligaciones particulares del estado y oficio, según las cuales ha de ser cada uno particularmente juzgado, Valencia, casas de Iuan Chrysostomo Garriz, junto al Molino de Rouella, 1613; Pedro DE Guzmán: Los bienes del honesto trabajo y daños de la ociosidad, en ocho discursos, Madrid: Imprenta Real, 1614.

38. Luis de la Puente: Segundo tomo de la perfección..., p. 77

39. Ibidem, p. 624

40. Ibidem, p. 623. Sobre este peligro y en la misma línea avisaría unos años más tarde NiEREMBERG, Obras y dias..., fols. $46 \mathrm{r}-\mathrm{v}$. 
virtuosa vigilando y guardando a sus súbditos, deshaciendo agravios y actuando en bien de la república. Para ello, lo primero de todo era clarificar qué es lo que se entendía por justicia y lo que significaba ser un rey justo. En ese sentido, implicaría dar a cada uno lo que le pertenecía por merecimiento y ley, sirviendo de ejemplo respecto a su cumplimiento, ya que no se encontraba al margen de ella. Respecto a la relación del monarca con la ley, el jesuita llega a insinuar que el soberano sería la ley personificada y que su comportamiento podía ser razón para sancionar y confirmar un decreto o derogarlo. De esta forma, el cumplimiento recto era obligatorio, puesto que si el rey actuaba en contra de la propia norma, daría pábulo a que delincuentes y pecadores vieran legitimadas sus malas acciones. ${ }^{41}$ Por consiguiente, el monarca, como máximo legislador (o ley misma) sería también concebido como el máximo tribunal de justicia al que una persona podía apelar, tal y como se venía practicando desde la Edad Media. En este sentido, resulta interesante la comparación que La Puente hace de la administración judicial del rey (civil y criminal), con la que llevan a cabo en la Iglesia el papa y los obispos, comprendiendo una delimitación entre las dos jurisdicciones, con sus propios jueces y leyes.$^{42}$ Esta cuestión es importante porque, como señalamos al principio del apartado anterior, la Monarquía Hispánica se encontraba a la altura de 1613 en pleno proceso de acercamiento a las disposiciones papales después de que durante el reinado de Felipe II se hubieran producido choques en materia de jurisdicción por los recursos de fuerza y la respuesta pontificia de la bula In coena Domini. ${ }^{43}$

$\mathrm{Al}$ igual que expresaba respecto al consejo, La Puente señalaba la importancia de que el rey hiciera uso de otros para ayudarle a gobernar bajo la ley la justicia. En este caso, más que por tener puntos de vista diferentes, porque era materialmente imposible que atendiera a todos los asuntos y decidiera justamente. Por ello, debía rodearse de una serie de funcionarios expertos en legislación y jurisdicción que se ocuparan de la mayor parte de los casos, quedando el rey como último tribunal de apelación y para los asuntos de mayor gravedad.

Estos funcionarios judiciales debían caracterizarse por su vejez (y experiencia), por ser de calidad y capacidades conocidas por el monarca para evitar ser engañado con la elección y por tener un amplio conocimiento de la jurisprudencia, tanto a nivel teórico, como práctico. Otros atributos serían el sosiego, la paciencia y la tranquilidad a la hora de escuchar los testimonios y tomar las decisiones. No debían dejarse dominar por las pasiones, ni apre-

41. Ibidem, pp. 573-574; JuAn Eusebio Nieremberg: Corona virtuosa..., p. 55.

42. Ibidem, p. 628.

43. Beatriz CÁrCeles de GeA: «El recurso de fuerza en los conflictos entre Felipe II y el Papado: la plenitudo quaedam iuris», Espacio, tiempo y forma. Serie IV, Historia moderna, 13, 2000, pp. 11-60. 
surarse en resolver un pleito sin escuchar a todas las partes involucradas. ${ }^{44}$ Todo ello, sin que se extendieran demasiado los asuntos en tiempo.

A partir de aquí, el jesuita hacía una serie de avisos sobre la procedencia que debían tener estos funcionarios regios. El primero de todos, que atendiera a la variedad de lugares y linajes a los que pertenecieran para evitar que se perjudicara a aquellos individuos de familias desacordes con la del juez o que procedieran de lugares que mantuvieran algún tipo de pleito de jurisdicción con el suyo. El segundo era una limitación social, puesto que, al contrario de lo señalado para los consejeros, en el caso jurídico sí que planteaba impedimentos para que ocupasen estos cargos aquellos que no fueran nobles. Esta restricción vendría provocada por factores como la autoridad y el acceso a la educación. Este último era fundamental porque, lógicamente, el juez debía ser experto en Derecho y solo se adquiría ese conocimiento si se estudiaba en la universidad. A pesar del crecimiento del número de centros que hubo desde los Reyes Católicos, en general era algo limitado a las grandes familias, nobles y oligarquías urbanas, especialmente si pensamos en la alta justicia. Por otra parte, La Puente defendía que la nobleza de un juez le aportaría autoridad y poder y reduciría en la medida de lo posible su corruptibilidad. Ni tendría temor de juzgar a un igual, por muy alta distinción que tuviera, si se pudiera comprar su favor, salvo que fuera una persona ambiciosa y corrompible. ${ }^{45}$ A pesar de ello, proponía el pago de un sueldo por el trabajo realizado.

Finalmente, en cuanto a la forma de desarrollar el trabajo judicial en sí mismo, La Puente no se fija en instituciones, más que en el propio tribunal, sin hacer mención a las chancillerías, ni a las audiencias, por ejemplo. Expresa la atención a los testimonios de los pleiteantes, a la resolución «juzgando del hecho por las reglas del derecho» y que el juez fuera ayudado por oficiales o colaboradores que tuvieran conocimiento de la materia, pero sin una limitación socioeconómica, puesto que «la riqueza no es causa bastante para ser elegido, como ni la pobreza para ser desechado». ${ }^{46}$

En el ejercicio de la justicia avisa de dos cuestiones. Por una parte, al igual que había señalado respecto al monarca, siempre será mejor prevenir que curar, puesto que «mayor bien hace a la República atajando los hurtos y homicidios, que castigando a los ladrones y homicidas, como [...] hacer buenos a los ciudadanos que quitar la vida a los malos». ${ }^{47}$ Por otra, avisa de cuáles podían ser los principales peligros para la justicia: los mercaderes, por los engaños en los pesos y medidas, los precios excesivos y el falso juramento; los tahúres, por jurar y perjurar, aprovechándose de los ociosos y codiciosos;

\footnotetext{
44. Luis de la Puente: Segundo tomo de la perfección..., pp. 635 y 645.

45. Ibidem, p. 634.

46. Ibidem, p. 642

47. Ibidem, pp. 636, 351.
} 
y los oficiales corruptos, que aprovechan su posición en la administración para engañar a sus clientes. ${ }^{48}$

En tercer lugar, y para finalizar este análisis de la obra lapontina, la utilidad que tendría el ejército dentro del ejercicio de la prudencia y el gobierno. La concepción que tenía La Puente de este instrumento no sería únicamente el tradicional, basado en las tropas y soldados que permitieran al Estado defender sus territorios o invadir otros, cuestiones sobre las que volveremos a continuación. El uso al que se refiere el jesuita es el de, en todo momento, hacer cumplir la justicia, tanto dentro, como fuera de sus fronteras y dominios. Así, a nivel interno identificaría, en cierta manera, al ejército con la policía, asignándole como una de sus labores el cumplimiento de la justicia, «castigando a los rebeldes, reprimiendo a los revoltosos, librando a los justos y conservando en paz a todos». ${ }^{49}$ Poco más se indica al respecto, sin incidir en la existencia de oficiales dependientes de la administración civil y judicial que se encargaran de ello, ni cuáles debían de ser sus atributos. Por el contenido general de la obra, se entiende que debían regirse por el respeto a la ley y la obediencia recta a los mandatos de sus superiores, algo que La Puente, como jesuita, tendría muy en cuenta. ${ }^{50}$

Más extensión sí merece lo que podemos relacionar más directamente con el ejército y la milicia. En este sentido, al igual que hicieron otros teóricos políticos, incluyéndose jesuitas como Suárez, Mariana, Ribadeneyra y Juan Azor, otro moralista. ${ }^{51}$ La Puente alude nuevamente al providencialismo que comentamos unas páginas más arriba para señalar la absoluta necesidad del conflicto militar, ante lo que solo se podía hacer era intentar tener el favor divino en la disputa. Solo admitiría dos circunstancias en las que estaría justificado el esfuerzo bélico: la defensa justa de la república o actuar para librar de la injusticia a los que estaban oprimidos. Frente a ello, se deslegitimaría

48. Ibidem, pp. 649-650.

49. Ibidem, p. 664.

50. La obediencia ciega y el respeto a la jerarquía fue uno de los elementos que la Compañía de Jesús trató de relacionar desde el principio con su organización y propia forma de ser. Sin embargo, esa aparente conjunción de pareceres en una misma dirección también fue causa de discordia en algunos momentos. DORIS MORENO: «La aportación española al debate sobre la obediencia ciega en la Compañía de Jesús durante el Papado de Sixto V (1585-1590)», Investigaciones históricas, 33, 2013, pp. 63-88; Doris MorenO: «Obediencias negociadas y desobediencias silenciadas en la Compañía de Jesús en España, ss. XVI-XVII», Hispania, vol. 74, n² 248, 2014, pp. 661-686; JUlián José LOZANO NAVARRO: «Los jesuitas, paradigmas del orden, la obediencia y la dependencia», Historia social, 65, 2009, pp. 113-124; Silvia MostacCio: Early Modern Jesuits between Obedience and Conscience during the Generalate of Claudio Acquaviva (15811615), Ashgate, 2014.

51. Para la concepción que estos autores tenían de la guerra justa: LuCiAno Pereña Vicente: Tratado de la guerra en Francisco Suárez, Madrid, CSIC, 2 vols., 1954; Francisco José Aranda Pérez y David MARTín López: «Pensamiento político more Societatis Jesu: entre la teología moral y la razón de estado», en José Martínez Millán, Henar Pizarro Llorente y Esther Jiménez Pablo (coords.): Los jesuitas: religión, politica y educación (siglos XVI-XVIII), Madrid, Polifemo, 2012, vol. 2, pp. 1320-1338. JUAN Azor: Institutionum moralium, Coloniae Agrippinae, 1608, vol. 2, p. 1680. 
toda aquella invasión en territorio ajeno para «ganar gloria en el mundo, o [...] por ensanchar su patrimonio con nuevas Provincias». ${ }^{52}$

$\mathrm{Al}$ igual que en los anteriores instrumentos, también reserva un espacio a hablar de los oficiales encargados del mismo, refiriéndose de una forma muy teórica y a priori. Señala que el soldado debía estar preparado física y mentalmente, sin establecer preferencias por un estado y/o estamento social: los nobles tenían los medios para ejercitarse en las armas y conocer la estrategia militar; por otra parte, los campesinos tenían unos condicionantes físicos que les permitían hacer frente al trabajo por muy adversa que fuera la meteorología. La única cuestión que plantea para el soldado es que tenía que estar centrado en el momento y el lugar de la batalla, sin pensar en sus posesiones, en lo que dejaba en su casa y en el temor por perder la vida y no volver a ver a sus familiares. Los graves perjuicios que esa desconcentración provocaría, lo situarían dentro del listado de motivos de exención del cumplimiento militar y de elementos que tenían que ser alejados de la vida castrense. Entre estos últimos, el primordial y muy necesario era el pecado de la lujuria, por ser una grave distracción para la mente del soldado y porque les impediría ser merecedores ante Dios de la victoria..$^{53}$ Una vez más, como vemos, se cruza el providencialismo dentro de la teoría lapontina.

El planteamiento que hace La Puente del ámbito militar se muestra muy teórico (aparte del enfoque moral) por dos aspectos, aparte de porque no entra en disquisiciones de estrategia o armamento: por una parte, señala que el soldado tenía que estar contento y pagado por su rey para evitar «buscar por malos medios otro sustento», una situación que la historiografía militar de las últimas décadas ha demostrado ampliamente que no se cumplía; por otra, la ligera referencia que hace a las órdenes militares, a cuyos miembros señala como los que cumplirían de manera más cercana sus planteamientos morales respecto a la milicia, por el carácter religioso que tendrían. Pero en ninguno de los dos casos entra en detalle sobre la soldada o el papel de los caballeros de hábito.

En todo caso y a modo de conclusión de este instrumento de gobierno, La Puente no se centra únicamente en las fuerzas militares al servicio del monarca para reflejar los momentos en los que debía actuar rectamente, sino que lo sitúa todo en torno a la fortaleza y la templanza de espíritu que debía ejercer todo individuo en su vida diaria. Junto al esfuerzo de capitanes y soldados en la batalla, también habla de los gobernadores, el resto de los ciudadanos y, finalmente, los mártires, aquellos «que fueron fuertes en la batalla, peleando contra los demonios y tiranos, dejándose despedazar los cuerpos y permaneciendo como inmutables por no faltar en la confesión de la Fe, ni en la virtud que profesaban».54

\footnotetext{
52. Luis de la Puente: Segundo tomo de la perfección..., pp. 666-667.

53. Ibidem, pp. 669 y 671-672.

54. Ibidem, p. 655
} 


\section{CONCLUSIONES}

A modo de colofón, las enseñanzas políticas que Luis de la Puente mostraba en su obra remiten directamente a conceptos como el providencialismo, la razón de Estado católica, la teocracia y el gobierno político de la moral. Todos conceptos religiosos con la prudencia como elemento cardinal del gobierno, hasta el punto de identificarse y confundirse con el propio concepto de lo político. La moral católica configuraría la identidad del individuo y su cotidianidad con independencia de su posición estamental y de las ocupaciones a las que se dedicaría. El seguimiento de los mandatos de la Iglesia católica, transmitidos a través de libros como los de este jesuita, y su cumplimiento, seguirían, según estos autores, a llevar una vida plena, incluso calificada como feliz. Ello, en el contexto en el que se sitúa la obra, nos dirige a pensar en esa pugna entre lo espiritual y lo temporal y la estrategia seguida por la Iglesia católica para, dirigiéndose al sentir del individuo, le empujara hacia un sentimiento de pertenencia a una comunidad universal bajo el gobierno del pontífice romano, en lugar del arraigo y fidelidad a un rey temporal.

La Puente transmite en sus páginas un estilo de vida basado en preceptos morales que inundarían todos los aspectos de la vida humana. El caso del gobierno, en cualquiera de sus niveles, no sería una excepción e incluso se situaría, de la mano de la prudencia y bajo la moral católica, como el más alto lugar en el que poder desarrollar esa forma de afrontar los avatares diarios.

\section{BIBLIOGRAFÍA}

Abad, Camilo: El venerable P. Luis de la Puente de la Compañía de Jesús. Sus libros y su doctrina espiritual, Santander, 1954.

-: Vida y escritos del V. P. Luis de la Puente de la Compañía de Jesús (1554-1624), Santander, 1957.

Alegambe, Felipe: Bibliotheca scriptorum Societatis Iesu, Antuerpiae, 1643

Alvarez-Ossorio Alvariño, Antonio: «Virtud coronada: Carlos II y la piedad de la Casa de Austria», en Pablo Fernández Albaladejo, Virgilio Pinto Crespo y José Martínez Millán (coords.): Política, religión e inquisición en la España Moderna, Madrid, 1996, pp. 29-57.

Aranda Pérez Francisco, José y Martín López, David: «Pensamiento político more Societatis Jesu: entre la teología moral y la razón de estado», en JosÉ MARTínez Millán, Henar Pizarro Llorente y Esther Jiménez Pablo (coords.): Los jesuitas: religión, política y educación (siglos XVI-XVIII), Madrid, Polifemo, 2012, vol. 2, pp. 1309-1356.

Azor, JuAn: Institutionum moralium, Coloniae Agrippinae, 1608, vol. 2, p. 1680.

Burrieza Sánchez, Javier: «La Antigua Compañía de Jesús (siglos XVI-XVIII)», en Teófanes Egido López (coor.): Los jesuitas en España y en el mundo hispánico, Madrid, Marcial Pons, 2004, pp. 27-223. 
-: «Los jesuitas como fuerza intelectual política», en Francisco José Aranda PÉrez y José Damião Rodrigues (eds.): De Re Publica Hispaniae. Una vindicación de la cultura política en los reinos ibéricos en la primera modernidad, Madrid, Sílex, pp. 227-264.

CÁRCELES DE Gea, BeAtriz: «El recurso de fuerza en los conflictos entre Felipe II y el Papado: la plenitudo quaedam iuris», Espacio, tiempo y forma. Serie IV, Historia moderna, 13, 2000, pp. 11-60.

Centenera Sánchez-Seco, Fernando: El tiranicidio en los escritos de Juan de Mariana, Madrid, Dykinson, 2009.

Chaparro, Sandra: Providentia. El discurso politico providencialista español de los siglos XVI Y XVII, Madrid, Comillas, 2012.

Escrivá, Francisco: Discursos de los estados de las obligaciones particulares del estado y oficio, según las cuales ha de ser cada uno particularmente juzgado, Valencia, casas de Iuan Chrysostomo Garriz, junto al Molino de Rouella, 1613.

-: Obras y días. Manual de señores y príncipes en que se propone con su pureza y rigor la especulación y ejecución política, económica y particular de todas las virtudes, Madrid, 1629.

García Oro, José y Portela Silva, Ma José: «Los frailes descalzos. La nueva reforma del Barroco», en Archivo Ibero-Americano, 60, 2000, pp. 511-586.

García Oro, JosÉ: «Observantes, recoletos, descalzos. La Monarquía católica y el reformismo religioso del siglo XVI», en Teófanes Egido López (coor.): Actas del Congreso Internacional Sanjuanista, Ávila, 1991, vol. II, 53-97.

Guzmán, Pedro de: Los bienes del honesto trabajo y daños de la ociosidad, en ocho discursos, Madrid: Imprenta Real, 1614.

IÑurritegui Rodríguez, José María: «Filósofos y santos: la Philosophia moral de Juan Torres y la definición de la cultura política católica», en Antonio Mestre Sanchís, Pablo Fernández Albaladejo y Enrique Giménez López (coords.): Monarquía, Imperio y pueblos en la España Moderna, Universidad de Alicante, Asociación Española de Historia Moderna, 1997, vol. 1, p. 654.

Lozano Navarro, Julián JosÉ: «Los jesuitas, paradigmas del orden, la obediencia y la dependencia», Historia social, 65, 2009, pp. 113-124

-: La Compañía de Jesús y el Poder en la España de los Austrias, Madrid: Cátedra, 2005.

Maravall, José Antonio: «La corriente doctrinal del tacitismo político en España», en Estudios de Historia del Pensamiento Español, Madrid, CEPC, 1999, vol. 3, pp. 75-98.

MARTín López, DAvid: «La virtud familiar en la tratadística moral jesuítica entre los siglos XVI y XVII», en MANUel RIVERo RodríGuez (coor.): Nobleza hispana, nobleza cristiana: la Orden de San Juan, Madrid, Polifemo, 2009, vol. 1, pp. 257-298.

-: «La conceptualización del Príncipe Christiano en la tratadística jesuítica entre los siglos XVI y XVII», en Antonio Jiménez Estrella y Julián José Lozano Navarro (eds.): Actas de la XI Reunión Científica de la Fundación Española de Historia Moderna, Granada, FEHM, 2012, vol. 1, pp. 113-123.

Martínez Millán, José y Visceglia, Ma Antonietta (coords.): La monarquía de Felipe III, Madrid: Mapfre, vol. 1, 2007.

Merle, Alexandra: «El De Rege de Juan de Mariana (1599) y la cuestión del tiranicidio: ¿un discurso de ruptura?», Criticón, 120-121, 2014, pp. 89-102.

Montesinos Castañeda, María: «Prudente gobierno: la prudencia en el gobernante», en Potestas. Estudios del Mundo Clásico e Historia del Arte, 14, 2019, pp. 61-83.

Moreno, Doris: «La aportación española al debate sobre la obediencia ciega en la Compañía de Jesús durante el Papado de Sixto V (1585-1590), Investigaciones históricas, 33, 2013, pp. 63-88.

-: «Obediencias negociadas y desobediencias silenciadas en la Compañía de Jesús en España, ss. XVI-XVII», Hispania, vol. 74, n 248, 2014, pp. 661-686.

Mostaccio, Silvia: Early Modern Jesuits between Obedience and Conscience during the Generalate of Claudio Acquaviva (1581-1615), Ashgate, 2014. 
Nieremberg, Juan Eusebio: Corona virtuosa y virtud coronada. En que se proponen los frutos de la virtud de un Príncipe, juntamente con los heroicos exemplos de virtudes de los emperadores de la casa de Austria y Reyes de España, Madrid, por Francisco Maroto, a costa de Gabriel de León, mercader de libros, 1643.

Puente, Luis DE LA: Segundo tomo de la perfección del christiano en los estados y oficios de las tres repúblicas, seglar, eclesiástica y religiosa. Tratase más particularmente de la seglar, Valladolid, por Francisco Fernández de CórdobA, 1613.

Ribadeneyra, Pedro de: Tratado de la religión y virtudes que deve tener el Príncipe Christiano para gobernar y conservar sus Estados, Madrid: Imprenta de P. Madrigal, 1595.

Sommervogel, Carlos: Bibliothèque de la Compagnie de Jésus, Bruselas, París, tomo VI.

Zafra, RAfael: «El prudente Tiziano y su emblema de la prudencia», en Potestas. Estudios del Mundo Clásico e Historia del Arte, 3, 2010, pp. 123-146. 